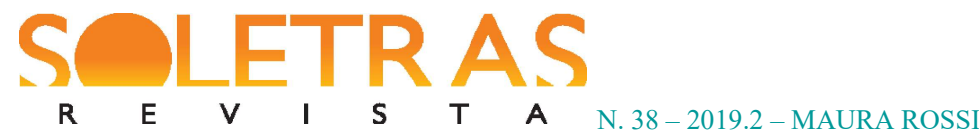

\title{
La maquinaria narrativa de Alberto Méndez ante la entropía del trauma. Acerca de Los girasoles ciegos
}

\author{
Maura Rossi ${ }^{1}$
}

\begin{abstract}
Resumen: Los girasoles ciegos de Alberto Méndez es una colección de cuatro cuentos publicada en el año 2004 en el contexto de la entonces recién revitalizada 'narrativa de la memoria', dentro del marco de la literatura española ultracontemporánea. Objetivo de este trabajo es la formulación de un análisis pormenorizado de algunos aspectos que vinculan el contenido de las historias narradas con las características técnicas del género elegido, con el fin de descifrar la declinación del cuento llevada a cabo por Méndez y su aportación en el debate trans-literario sobre el recuerdo compartido del trauma de la guerra civil y el franquismo. Finalidad última de la argumentaciones comentar el concepto de 'derrota universal' propuesto por el autor, sus distintas modulaciones dentro del texto y las modalidades de configuración de un duelo inclusivo que pacifique, por fin, la memoria heredada de un bache histórico tan reciente como controvertido.
\end{abstract}

Palabras clave: Alberto Méndez. Los girasoles ciegos. Postmemoria. Guerra civil española. Cuento.

En el panorama de la literatura memorialista ultracontemporánea, Los girasoles ciegos de Alberto Méndez, una colección de cuatro cuentos entrelazados publicada por primera vez a principios del año 2004, resulta ser una obra peculiar tanto por su extraordinaria calidad literaria y por la consistente respuesta positiva que sigue cobrando, quince años después, entre el público español e internacional, como por su estatus excepcional de opera prima de un escritor maduro que, al haber fallecido en diciembre del mismo año a causa de una enfermedad degenerativa, apenas pudo comentar su creación, que justamente en ese momento empezaba a cosechar premios literarios y se convertía en objeto de las primeras traducciones a otros idiomas ${ }^{2}$. Formado por cuatro piezas que, como se nota aun tras una lectura superficial, presentan características formales y de contenido por lo general comparables y recurrentes, el ciclo de cuentos invita a ser leído como un conjunto plurivocal cuyo mensaje global apunta, desde la distancia otorgada por la perspectiva transgeneracional, a la configuración colectiva

\footnotetext{
${ }^{1}$ Doutora pelo Departamento de Ciências Linguísticas, Filológicas e Literárias pela Università degli Studi di Padova. Itália. E-mail: maura.rossi@unipd.it io https://orcid.org/0000-0003-0343-814X

${ }^{2}$ Entre otros galardones, recuerdo el "Premio Setenil" (fallado en diciembre de 2004), el "Premio de la Crítica" y el "Premio Nacional de Narrativa" (ambos otorgados póstumos en 2005).
} 


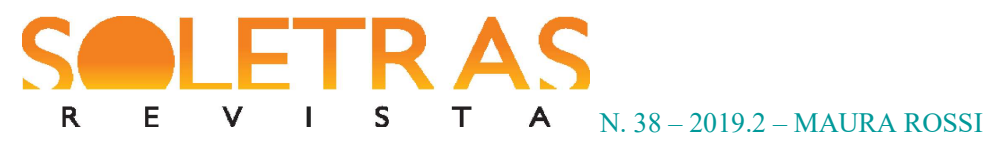

de un duelo compartido - eso es, no ya banderizo, sino común, de todos los españoles- ${ }^{3}$, una sugestión que vertebra el epígrafe del texto, tomada a préstamo de Carlos Piera:

Superar exige asumir; no pasar página o echar en el olvido. En el caso de una tragedia requiere, inexcusablemente, la labor del duelo, que es del todo independiente de que haya o no reconciliación y perdón. En España no se ha cumplido con el duelo, que es, entre otras cosas, el reconocimiento público de que algo es trágico y, sobre todo, de que es irreparable. Por el contrario, se festeja una vez y otra, en la relativa normalidad adquirida, la confusión sea ya materia de historia y el que no lo sea aún, y en cierto modo para siempre, de vida y ausencia de vida. El duelo no es ni siquiera cuestión de recuerdo: no corresponde al momento en que uno recuerda a un muerto, un recuerdo que puede ser doloroso o consolador; sino a aquel en que se patentiza su ausencia definitiva. Es hacer nuestra la existencia de un vacío. (MÉNDEZ, 2008, s.n.)

La dualidad a primera vista estridente entre unidad interpretativa y especificidad de cada pieza se traduce en Los girasoles ciegos en una estrecha vinculación entre el contenido de los cuatro cuentos y su estructura comprimida y elíptica, basada en todo momento en una búsqueda milimétrica de la esencialidad y en la repetición de la misma dinámica interna dentro de cada texto individual, con vistas a la enfatización de la "cohesión narrativa" que rige el proyecto (JOSÉ MARÍA POZUELO YVANCOS en LÓPEZ GUIL; ALBIZU YEREGUI, 2015,p. 201).

Los primeros indicios que sugieren cierta solidaridad de mensaje $-\mathrm{y}$, entonces, de escritura y lectura- entre las cuatro partes se encuentran en el paratexto del conjunto, y en las primeras ediciones van diseminados ya a partir de las secciones superficialmente más visibles, eso es, la contratapa y la solapa, las primeras porciones del objeto-libro que un comprador potencial ojea al barajar la lectura del mismo ${ }^{4}$. Al mismo tiempo, abogan decididamente por

\footnotetext{
${ }^{3}$ Anthony Nuckols (2011,p. 180) habla justamente del uso de la narración postmemorialista como "instrumento del duelo".

${ }^{4}$ Albizu Yeregui (2009, p. 69) subraya que la contratapa de las ediciones Anagrama de 2004 describe el texto genéricamente como un "libro [que] es un regreso a las historias reales de la posguerra, [...] cuatro historias [de los tiempos del silencio] sutilmente engarzadas entre sí", una caracterización también mencionada en la lectura de Fernando Valls (en LÓPEZ GUIL; ALBIZU YEREGUI, 2015, p. 66). Señalo que varios de los críticos que han analizado Los Girasoles Ciegos han relevado que, tanto en su aparato paratextual como en las declaraciones de Méndez, la obra apenas queda enmarcada desde el punto de vista del género literario, acaso a raíz de una ambigüedad voluntaria debida a la co-presencia en el texto de elementos típicos del género cuento y "nexos propios de la novela, [que integran] las unidades jerárquicamente 'inferiores' en otra 'superior' susceptible de una lectura global” (ALBIZU YEREGUI, 2009, p. 70).
} 
un acercamiento 'unitario' a la obra la dedicatoria -“A Lucas Portilla (in memoriam). A Chema y Juan Portilla, que conocen la ausencia" (MÉNDEZ, 2008, s.n.)- y el ya citado epígrafe inicial, dos elementos que, por su colocación, quedan percibidos como una introducción al conjunto, y no exclusivamente al primer relato,a la vez que formulan una propuesta temática programática vinculada con un dolor "irreparable" y "trágico", ocasionado por una "ausencia" que todavía no se ha hecho públicamente "patente" y que es preciso "asumir" dentro del discurso público español si se quiere favorecer la elaboración de un “duelo" transversal (MÉNDEZ, 2008, s.n.).

El título de la obra, parcialmente coincidente con el "intertítulo" (ALBIZU YEREGUI, 2009, p. 73) de la "Cuarta derrota", es otra medida de conexión entre las cuatro partes del texto, ya que su carga metafórica, en un primer momento críptica, tan solo recibe su clave interpretativa hacia la conclusión, donde queda explicitado que son 'girasoles ciegos' todos los españoles -representados por la amalgama de los distintos personajes que aparecen en los cuentos -, unánimemente derrotados por la guerra cainita independiente de su colocación política dentro del bando de los vencedores o de los vencidos. Contextualmente, entrelazan los cuatro cuentos los títulos parciales de cada uno, organizados según una estructura tripartita que se repite y que informa ante todo de una progresión cronológica (1939; 1940; 1941; 1942) $)^{5}$ y numérica ("Primera derrota", "Segunda derrota", "Tercera derrota" y "Cuarta derrota", como si se tratara, en efecto, de los capítulos de una novela). Orsini-Saillet (2006) nota que "la enumeración de las derrotas y la ostentación de la cronología invitan a leer la obra de manera lineal, a considerar cada relato como una variación sobre el mismo tema”, aunque al mismo tiempo el breve sintagma que sigue la conjunción 'o' -que más que disyunción parece indicar equivalencia- colocada en todos los títulos después de la fecha evidencia su especificidad, al ser distinto para cada cuento ${ }^{6}$.

Más allá de la transversalidad estructural que se observará a continuación, también cabe observar correspondencias internas que pertenecen a la dimensión textual, eso es, a la esfera temática, léxica y estilística. El dato textual que quizás resulte superficialmente más

\footnotetext{
${ }^{5}$ Simone Trecca (2012, p. 133) habla de "arco cronologico compatto".

${ }^{6}$ Los títulos parciales son "Si el corazón pensara dejaría de latir" para la "Primera derrota"; "Manuscrito encontrado en el olvido" para la segunda; "El idioma de los muertos" para la tercera; y "Los girasoles ciegos" para la cuarta (MÉNDEZ, p. 11, 37, 59 y 103). Nótese que el segundo cuento va precedido por la anotación "[e]stecapítulo, modificado, fue finalista del Premio Internacional de cuentos Max Aub 2002 y publicado por la Fundación Max Aub. Agradezco la autorización para incorporarlo a su lugar original" (MÉNDEZ, 2008,, p. 37, énfasis mío), que caracteriza la unidad como parte de un 'todo' de mayor extensión.
} 


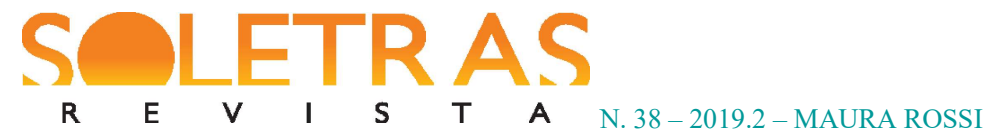

evidente a la hora de destacar cierta conexión entre las derrotas es la presencia 'desbordante' de algunos personajes más allá de los límites físicos de cada cuento, aunque el transvase no resulte imprescindible para la comprensión individual de las cuatro unidades ${ }^{7}$. Parece cobrar mayor relevancia, en cambio, una serie de correspondencias léxicas y de tono que concurren todas a la enfatización, matización y universalización del concepto de derrota, declinado según múltiples versiones, pero inexorablemente común entre todos los personajes de la obra $^{8}$.

En lo referente a la técnica narrativa, Los girasoles ciegos es una obra caracterizada por una elevada fragmentación de los puntos de vista, que dentro de cada derrota se entrecruzan y solapan polifónicamente, proporcionando diferentes versiones y modalidades expositivas acerca de la misma historia. Siguiendo un afán de pluralidad y un gusto por la ficcionalización del documento que resultan recurrentes en la narrativa transgeneracional de la memoria ${ }^{9}$, Méndez parece enfatizar a través de su poliperspectivismo la idea según la cual toda reconstrucción del pasado - sea esta ficcional o no lo sea - es en todo caso parcial y omisiva, con lo cual resulta en parte encomendada al lector/oyente/destinatario la tarea de combinación de las piezas del mosaico y reconstrucción de la imagen global.

Para empezar, los dos narradores en primera persona que abren la "Primera derrota" y la segunda se presentan como personajes que mantienen algún tipo de relación con la historia que cuentan, aunque no la protagonizan. Los dos quedan caracterizados desde el principio como 'investigadores' que pretendieron ahondar en las historias de los protagonistas de los cuentos -como se verá, el capitán Alegría y el joven autor del diario- $\mathrm{y}$, de hecho, junto al resultado final, también presentan un resumen del recorrido por medio del cual lograron recuperar los datos sobre los que se fundamenta la reconstrucción.

\footnotetext{
${ }^{7}$ Más específicamente, el Carlos Alegría de la "Primera derrota" es detenido en la tercera en la misma cárcel de Juan Senra, y la joven Elena, esposa del protagonista de la "Segunda derrota", queda fugazmente identificada como la hija del matrimonio Mazo que protagoniza la cuarta. Recuerdo que justamente el vínculo entre la "Segunda derrota" y la cuarta constituye la base de la elección temática adoptada en la transposición fílmica de Los girasoles ciegos (véase CUERDA, 2008).

${ }^{8}$ Entre las correspondencias de vocabulario más destacadas, señalo la reiteración de formas del verbo reflexivo 'acurrucarse', utilizado para describir análogas situaciones en las que los personajes se encogen y reducen manifestando sensaciones comunes de angustia, miedo y anonadamiento; la repetición del lexema 'desmadejado', empleado para representarla isotopía del cansancio; la alta incidencia de entradas -adjetivos sobre todo- que presentan prefijo 'des-' de privación; la 'reapropiación' de la ciudad de Madrid como paradigma de unidad entre los españoles (y la relativización, entonces, de su caracterización triunfalista como escenario preferente del triunfalismo franquista).

${ }^{9}$ Para una profundización véanse Bertrand de Muñoz (2011), Becerra Mayor (2015), Gómez-López Quiñones (2006), Martínez Rubio (2015) y Rossi (2016).
} 


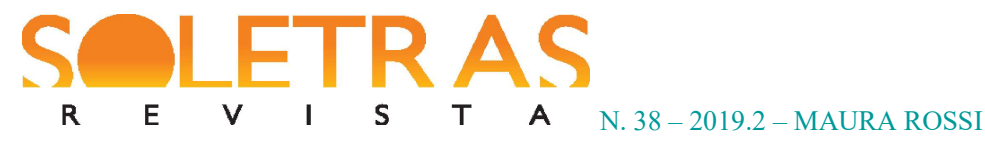

El narrador del primer cuento se esfuerza por proporcionar una apariencia objetiva a su exposición y "emplea, al referirse a sí mismo, el plural de modestia propio del discurso científico, [presentándose] como un compilador que nada ha inventado y que, por el contrario, se ha documentado muy bien al realizar la reconstrucción que nos ofrece" (ALBIZU YEREGUI, 2009,p. 74-5). Su recorrido narrativo procede como un calculado razonamiento académico elaborado a partir de datos pretendidamente documentales recuperados con esfuerzo, hasta el punto que el filtro de su voz prevalece netamente respecto a la del personaje. Aun así, se nota que la reconstrucción del narrador queda interferida a menudo por pasajes que no es posible atribuir a su elocuencia grave, sino que corresponden a las supuestas palabras o pensamientos de Alegría; pese a clarificar desde el principio que "presuponer lo que piensa el protagonista de nuestra historia es solo una forma de explicar los hechos que nos consta que ocurrieron" (MÉNDEZ, 2008, p. 20), al tratar de especular rigurosamente acerca de las reflexiones del capitán el narrador se deja llevar por ellas hasta el punto que abandona su lenguaje formal y expresa sin mediaciones ni advertencias el flujo de los pensamientos del objeto de su estudio, llegando a producir una exposición más literaria que académica.

Diferentes son los planteamientos iniciales de la "Segunda derrota", donde el narrador en primera persona singular se presenta en su nota introductora como un filólogo cuya atención hacia el manuscrito que se dispone a transcribir ha sido despertada por la presencia de un detalle literario -la pintada "infame turba de nocturnas aves" (MÉNDEZ, 2008, p. 40) en una pared del lugar donde éste fue encontrado. El narrador "lleva a cabo un verdadero trabajo de genética textual, analizando lo tachado, la evolución de la caligrafía, la organización de la página, sacando provecho de la materialidad del cuaderno, comentando lo no verbal" (ORSINI-SAILLET, 2006); no obstante, no su labor investigadora, sino el material analizado acaba convirtiéndose en el eje del cuento, a medida que las páginas del diario copiado y publicado ocupan por entero el espacio narrativo. Aun así, se registra una fuerte interdependencia entre los dos componentes narrativos de la derrota, debido a que el flujo temático sí mana esencialmente del cuaderno del poeta, pero es el editor quien lo encauza y quien determina entonces su percepción -y parcialmente también su interpretación. Por lo que se puede apreciar, la escritura del diario y su transcripción se colocan en dos niveles distintos de posterioridad con respecto a la historia del protagonista, entre los que parece ser dominante la semi-inmediatez de la aportación del poeta, mientras que los comentarios interpuestos del editor producen la impresión de saltos reiterados entre un grado y otro de la reconstrucción. 


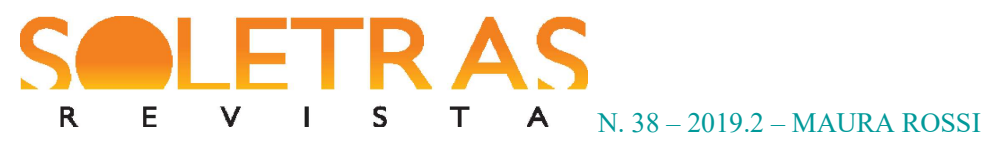

Concluye la narración la voz heterodiegética del editor, quien declara haber individuado un nombre y una identidad que podrían coincidir con los del autor del diario sobre la base de los pocos datos biográficos disponibles en el documento; sin embargo se confirma nuevamente un planteamiento más literario que historiográfico al cerrarse el texto con una reflexión personal: "si fue [Eulalio Ceballos Suárez] el autor de este cuaderno, lo escribió cuando tenía dieciocho años y creo que ésa no es edad para tanto sufrimiento" (MÉNDEZ, 2008, p. 57).

Esta compleja fragmentación de las voces y de los planos narrativos queda llevada al extremo en la "Cuarta derrota", donde el autor propone una alternancia organizada sistemáticamente entre tres narradores, sin proporcionar algún tipo de explicación acerca de los criterios de disposición de los fragmentos propuestos y de la relación que los conecta. La voz que abre el cuento es la del hermano Salvador, que, desde una posición comparable con la del poeta de la "Segunda derrota", trata de reconstruir su historia por medio de una carta en la que pretende formular una confesión dirigida a su padre espiritual al poco de verificarse los acontecimientos a los que hace alusión:“a pesar de que hoy he visto morir a un comunista, en todo lo demás, padre, he sido derrotado" (MÉNDEZ, 2008, p. 105). El segundo narrador también recupera (en primera persona singular, como el precedente) acontecimientos directamente relacionados con su biografía; sin embargo, resulta más complejo clasificar su testimonio debido a que, pese a tratarse sin duda de una narración posterior a lo contado, no se encuentran datos que permitan establecer ni las circunstancias en las que ésta se produjo, ni su colocación con respecto al tiempo de la historia. En lo referente a la primera cuestión, los pasajes atribuidos a Lorenzo Mazo tienen el semblante de un flujo ininterrumpido, pero ordenado de recuerdos: la impresión es que no sean memorias esparcidas, sino reflexiones ordenadas cuyo fin es justamente reconstruir los meses que precedieron la muerte de su padre Ricardo. No queda claro, sin embargo, si se trata de una contribución escrita u oral y, sobre todo, si Lorenzo la elabora por su propia iniciativa o solicitado por la curiosidad de un destinatario que tiene interés por esa parte específica del pasado de su interlocutor y que quizás formula preguntas de las que el cuento no conserva rastros. Al mismo tiempo, cabe notar que el objeto de la narración corresponde a episodios relativos a la niñez del narrador, mientras que la voz narrativa es netamente identificable como adulta, y reconoce en más de un pasaje la parcialidad de su memoria ya mermada por el paso del tiempo: 


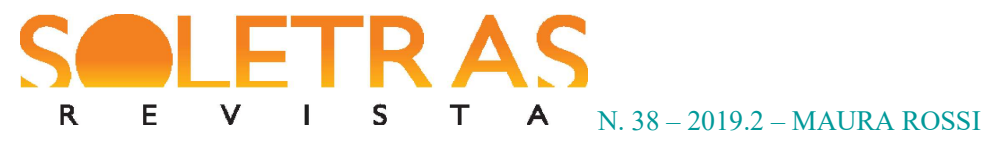

Quizás por eso recuerdo a mi padre joven, alto, escuálido y vigoroso abrazado a mi madre anciana, cansada y dulce. Recuerdo al Hermano Salvador con su sotana castrense acosando a mi madre cansada, anciana y dulce y a unos policías procaces insultando a mi madre anciana, cansada y dulce. Pero sobre todo recuerdo a un niño lleno de complicidades con su madre anciana, cansada y dulce, a la que no logro recordar como me dijeron que fue: joven, vigorosa y dulce. (MÉNDEZ, 2008, p. 107)

El tercer narrador de la "Cuarta derrota", al igual que el narrador de la tercera, pertenece a la tipología laxa del narrador omnisciente, aportando en tercera persona un punto de vista que no presenta ninguna conexión apreciable con la historia que relata, diferentemente de los narradores no-protagonistas de las derrotas primera y segunda, cuyas historias van intersecadas con las que ellos mismos reconstruyen. Se trata, en estos dos casos, de narradores que no son detectives de la memoria, sino más bien fabuladores. En la "Cuarta derrota", así como el relato de Lorenzo resulta ser independiente de la carta del hermano Salvador, la reconstrucción proporcionada por la tercera voz se desarrolla como una narración autónoma con respecto a los demás dos narradores ${ }^{10}$. A este propósito, evidencia Albizu Yeregui $(2009$, p. 80) que "cada una de las narraciones [de la Cuarta derrota] puede ser leída independientemente al igual que cada uno de los cuentos que componen el libro; y también al igual que éste, el conjunto de todas ellas presenta una unidad y coherencia interior". A estas alturas es necesario evidenciar que una característica peculiar de la "Cuarta derrota" es la apelación implícita a una labor de recomposición llevada a cabo por el lector, al cual se requiere que combine y supere los filtros narrativos ofrecidos por los narradores dejando explícita la invitación 'mnemógena' que rige toda la obra. Más específicamente, en la cuarta unidad se requiere al lector vaya juntando los datos procedentes de tres versiones parciales de la misma historia, interprete fuentes, conecte impresiones $\mathrm{y}$, donde no resulte posible recuperar más material, integre los huecos de información por medio de suposiciones. En esta óptica puede, entonces, suponerse que los varios narradores encarnen diferentes modalidades de registración del pasado, un abanico que abarca desde la expresión íntima de la memoria individual hasta su reconstrucción 'científica' o narración literaria, declinaciones todas que son medidas parciales de fijación de los acontecimientos traumáticos del pasado y que

\footnotetext{
${ }^{10}$ Nótese también que los tres narradores de la "Cuarta derrota" van diferenciados desde el punto de vista tipográfico, ya que los fragmentos atribuidos al Hermano Salvador son transcritos en cursiva, los recuerdos de Lorenzo en negrita, y la narración en tercera persona en redonda.
} 


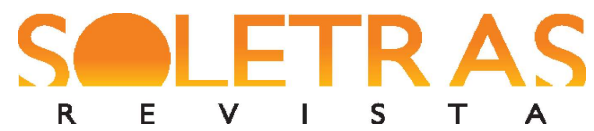

N. 38 - 2019.2 - MAURA ROSSI

contribuyen a una (re)configuración esperadamente plural e inclusiva de la memoria pública. Más aún, la yuxtaposición de voces múltiples llama la atención hacia la necesidad de adoptar a la hora de rememorar una perspectiva de conjunto, que favorezca la elaboración de una reconstrucción variada lo bastante como para que todos encuentren cabida en ella y puedan ver allí reflejados sus propios recuerdos personales o heredados ${ }^{11}$.

Si se intenta hacer referencia a la teoría -todavía notablemente inestable-delcuento para mejor orientarse en el análisis de las unidades narrativas que componen Los Girasoles Ciegos, cabe retomar la definición personal del género propuesta por el autor, quien se ocupó de comentar su elección formal en el discurso de aceptación del "Premio Setenil". En el breve escrito que leyó ante el jurado en Molina de Segura, Méndez define el género como una "narración breve de hechos inventados"12, al mismo tiempo que subraya que dicha opción compositiva se caracteriza formalmente por su

necesidad de sintetizar la narración y utilizar solo sus elementos esenciales: planteamiento sucinto, enredo esquemático, personajes paradigmáticos y desenlace sorpresivo. Todo esto ha generado una dosificación y un equilibrio interno, que convierten el cuento en algo imparable, vertiginoso. (MÉNDEZ, 2004) (13 $^{13}$

Antes de confrontar los "elementos esenciales" enumerados por Méndez con el armazón de cada uno de sus cuentos, cabe reflexionar acerca del valor que puede conferirse a la definición estilística arriba citada por lo que atañe al proyecto de escritura del texto. A este propósito, pese a cobrar la forma de una declaración oficial solamente aposteriori (es decir, después de la elaboración y publicación de la obra), la definición de Méndez parece tener el

\footnotetext{
${ }^{11}$ Al referirme a los recuerdos no estrictamente personales, pero sí asumidos como propios dentro del marco familiar o social retomo la noción de 'postmemoria' teorizada en Hirsch (2012). En el mismo contexto de transmisión de la memoria verbal a los herederos también cabe mencionar el concepto de 'postmemoria afiliativa', definida por Hirsch $(2012,15)$ como "the result of contemporaneity and generational connection with the literal second generation combined with structures of mediation that would be broadly appropriable, available, and indeed, compelling enough to encompass a larger collective in an organic web of transmission" (para una profundización, véase FABER, 2014).

${ }^{12}$ Según la lectura de Laurence Garino-Abel (2012) se trata de una narración que bascula entre pura invención y transposición literaria de memorias personales.

${ }^{13}$ El ensayo es el último escrito atribuido a Méndez del que se tenga noticia. Escribe Ignacio Martínez de Pisón (2005) en relación con la ceremonia de entrega que "[Méndez viajó] a Molina de Segura a recoger un premio por sus cuentos pocos días antes de morir y ya con la salud muy quebrantada" y, en efecto, el autor falleció en Madrid a los pocos días de recibir el galardón.
} 


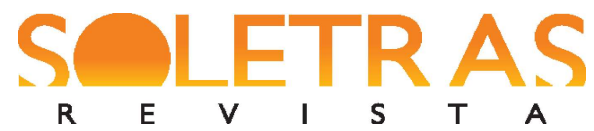

N. 38 - 2019.2 - MAURA ROSSI

talante de un acta programática; en otras palabras, queda percibida como una concepción fundacional de escritura, de estructura y de estilo que el autor tenía planteada antes de convertir su concepto en literatura y a la que fue adaptando el material que iba produciendo. La consideración que se acaba de formular induciría, entonces, a suponer que partiendo de una idea acerca de lo que iba a ser el contenido de su obra, el autor haya escogido la forma del cuento, esencial y al mismo tiempo plástica, pues la consideraba particularmente adecuada para sus planteamientos conceptuales y estéticos. La impresión de que el aspecto de cada uno de los cuentos que componen el libro se deba a una supresión meticulosa de toda porción de contenido que no resultara funcional para la formulación del mensaje queda confirmada por el mismo Méndez, quien en una entrevista con César Rendueles (2004) explica que

he ido quitando cosas. Originalmente el libro era mucho más largo. En concreto en el episodio de la cárcel había muchas páginas dedicadas a narrar la relación entre el chico de los piojos y Juan Senra. En esas páginas se explicaba el surgimiento de su amistad, pero me pareció más efectivo dejarlo sobreentendido. ${ }^{14}$

Verosímilmente, varias secciones del texto han sido progresivamente expurgadas del manuscrito finalmente publicado, sin embargo -y aquí estriba una porción consistente de la eficacia estilística de la obra- las "páginas" tachadas no resultan eliminadas de la dinámica de cada cuento, sino que su carga temática y narrativa sigue percibiéndose de manera difuminada y hasta queda potenciada mediante un empleo sistemático de la elipsis. A partir de unas pocas sugerencias temáticas lineales expresadas con palabras semánticamente cargadas surgen una serie de sugestiones, impresiones y solicitaciones emotivas que alcanzan de golpe al lector y lo dejan 'noqueado'. 15

Parte de la compresión de la que brota la prosa de Méndez reside en el supuesto carácter paradigmático de sus personajes, comunes y universales lo suficiente como para

\footnotetext{
${ }^{14}$ Una alusión más detallada acerca de esta esmerada labor de acortamiento la proporcionó Milagros Valdés, viuda del autor, quien declaró con ocasión de la atribución póstuma a la obra del "Premio Nacional de Narrativa" que "los dos últimos años antes de publicar Los Girasoles Ciegos [Méndez] se dedicó [...] a escribir miles de cuartillas que luego fue puliendo y puliendo hasta finalizar su trabajo" (citada en INTXAUSTI, 2005).

${ }^{15}$ Observa Cortázar $(1971,404)$ en unos de sus ensayos sobre el cuento que "la novela gana siempre por puntos, mientras que el cuento debe ganar por knock-out". Asimismo, señalo que Francis Lough (2017) propone para la obra de Méndez una lectura basada en los mecanismos afectivos.
} 


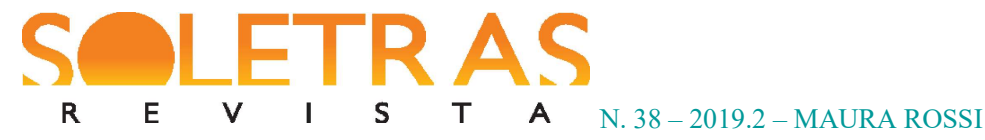

suscitar una honda participación por parte del lector, por lo general hilvanada alrededor de la condición omnicomprensiva de derrota existencial radicada en el trauma histórico. Más específicamente, pese a que una primera percepción de las tramas pueda llevar a interpretar como no comunes o excepcionales las vicisitudes de los varios personajes, no está de más suponer una cabida de las mismas dentro de la memoria familiar o, en cualquier caso, colectiva de todo lector. Así, al retratar historias enmarcadas dentro de los 'estados de excepción' que son un conflicto y una dictadura, Los girasoles ciegos despliega una gama de acontecimientos y condiciones de vida comunes en los años 1939-1942, muy probablemente reminiscentes de los recuerdos que circulan tanto en el micro-entorno social de cada español como dentro del debate mediático y político actualmente activo alrededor de la guerra civil y el franquismo. ${ }^{16}$ Los acontecimientos que forman la base del enredo de cada una de las derrotas coinciden, entonces, con eventos descomunales en tiempos de paz que, sin embargo, se convirtieron en ordinarios durante los años en los que se desarrollan, y que al formar parte de una porción todavía controvertida de la historia común resultan directa o indirectamente presentes dentro del patrimonio mnésico del lector español contemporáneo.

En esta medida, son paradigmáticos de diferentes condiciones vitales en tiempos de enfrentamientos intestinos el militar desecho por tantas batallas faltas de sensatez; el condenado que sobrevive a un fusilamiento apresurado; el disidente que va consumiéndose debido a las privaciones de un exilio incumplido que había encarnado una esperanza de libertad fuera de España; el prisionero torturado, privado de su propia identidad y sometido a juicios sumarios sobre la base exclusiva de su afiliación política; la familia desgarrada por la guerra; el intelectual fiel a la República escondido en su propia vivienda; el religioso sacudido en los fundamentos de su fe por la reciente experiencia castrense, en todo contraria a las enseñanzas aprendidas en el seminario. Se trata de facetas que constituyen declinaciones verosímiles del trauma a corto y largo plazo provocado por la guerra civil y la dictadura, una derrota que nada tiene que ver con las categorías histórica y política de los 'vencedores' y 'vencidos', en la medida en que resulta indiferenciada y generalizada. Como sugiere el autor por medio de la reiteración de la palabra en el título de cada cuento, dentro de Los girasoles ciegos todo sujeto es un derrotado por la guerra independiente del bando al que pertenezca, y como tal vive, se reconoce o queda identificado por los demás personajes, ya que en una

\footnotetext{
${ }^{16}$ A este propósito, siguiendo la teoría de Pierre Nora, Sara Santamaría (2007) reconoce a Los girasoles ciegos el estatus de lieu de mémoire narrativo.
} 


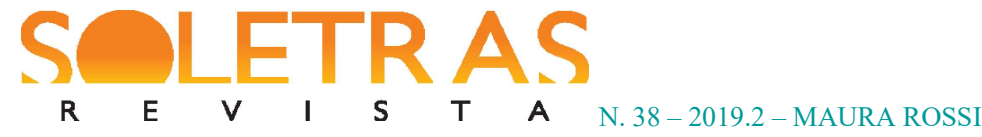

guerra entre hermanos la derrota se propaga al igual que una epidemia, sin hacer distinciones de color político, condición social o posicionamiento ideológico. En palabras del joven poeta de la "Segunda derrota":

morir no es contagioso. La derrota sí. Y me siento transmisor de esa epidemia. Allá donde yo vaya olerá a derrota. Y de derrota ha muerto Elena y de derrota morirá mi hijo al que todavía no he podido poner nombre. (MÉNDEZ, 2008, p. 45-6)

Así Carlos Alegría, miembro del ejército vencedor que no escogió su afiliación al azar sino por firmes afinidades ideológicas con los planteamientos iniciales de la facción sublevada, no renuncia a su pertenencia política al declararse un rendido -pues "un rendido es un enemigo derrotado, pero sigue siendo un enemigo" (MÉNDEZ, 2008, p. 15) - sino que reconoce que "en una guerra civil nadie vence, pierde todo el pueblo que ha sufrido" (MOLERO BENAVIDES, 2005). Por las mismas razones, otros derrotados 'insospechados' son los dos miembros del matrimonio Eymar en la "Tercera derrota", que han ganado una guerra y, sin embargo, han perdido a su único hijo. Violeta Eymar queda presentada desde el principio como el retrato viviendo de la derrota: es una "madre destrozada" y prematuramente “envejecida” (MÉNDEZ, 2008, p. 73-75) a la que ni siquiera la luz directa que pasa por el ventanal de la sala de interrogatorios logra iluminar; su marido, en cambio, pese a quedar identificado por el narrador como un hombre "desvaído" y "desvencijado" desde las primeras páginas, logra mantener cierta altivez de fachada gracias a su cargo oficial y a su uniforme, que le otorgan de derecho un puesto entre los vencedores. No obstante, tras escuchar la verdadera historia de su hijo, el juez ya no logra mentir a sí mismo acerca de su condición de derrotado, pues en ese momento entiende que la pérdida del ser querido no queda compensada ni siquiera por la posibilidad para la familia de lucir una memoria gloriosa - ¿cómo iba a olvidar a Miguelito? El héroe de su estirpe que había muerto solo para ser vengado" MÉNDEZ, 2008, p. 63) -, con lo cual lo que queda de la ausencia es solo un dolor irreparable que la retórica de la victoria no logra aliviar. Otro derrotado del bando vencedor es el hermano Salvador, un joven religioso engatusado por la verbosidad del lenguaje de la Cruzada y enviado al frente sin más preparación que la convicción de que es preciso erradicar a los 'rojos', pues “ellos pretendieron [...] modificar los designios del Señor” (MÉNDEZ, 


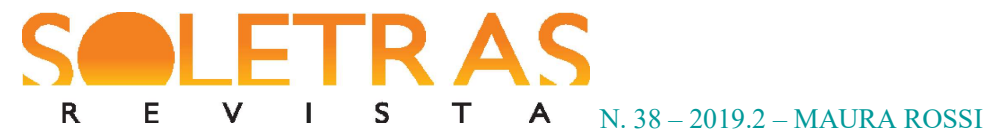

2008, p. 107). El trauma del combate derrota al cura aun antes de que éste logre regresar a Madrid y quede incorporado en el cuerpo docente de un colegio de párvulos: de hecho, escribe el hermano en su carta que "cuando fui arrojado a la vida, siempre preñada de corrupción y desorden, me sorprendió indefenso porque hasta que lo vi, Padre, yo no había tenido conocimiento del Mal.[...] Nunca intuí lo horrible que era el mundo. Fanfarrón, gregario, embustero, pecador y heroico. Poco a poco me fui desguarneciendo, como si yo estuviera perdiendo la batalla" (MÉNDEZ, 2008, p. 111). El adoctrinamiento impide que el religioso reconozca que su desvarío estriba en el estado de alteración emocional que le provocaron tres años de combates, con lo cual el cura culpa a Ricardo Mazo de haberle contagiado con su propia derrota al suicidarse tras ser desanidado. Pese a no individuar con precisión las causas que determinaron su estado, el diácono llega de todo modo a tomar conciencia de su condición de derrotado y se coloca tanto a principios como a finales de su carta dentro del "rebaño" de los miles de españoles condenados a vivir como "girasoles ciegos", es decir como sujetos desnortados, faltos de metas, de objetivos y de esperanzas (MÉNDEZ, 2008, p. 155). La derrota general, propia de un país entero y no solo de una de sus dos mitades, queda eficazmente resumida por el capitán Alegría, que al observar a un grupo de soldados de su propio bando redacta la siguiente nota:

\begin{abstract}
¿Son estos soldados que veo lánguidos y hastiados los que han ganado la guerra? No, ellos quieren regresar a sus hogares adonde no llegarán como militares victoriosos sino como extraños de la vida, como ausentes de lo propio, y se convertirán, poco a poco, en carne de vencidos. Se amalgamarán con quienes han sido derrotados, de los que solo se diferenciarán por el estigma de sus rencores contrapuestos. Terminarán temiendo, como el vencido, al vencedor real, que venció al ejército enemigo y al propio. (MÉNDEZ, 2008, p. 36)
\end{abstract}

En lo referente al planteamiento de las narraciones desarrolladas como cuentos, escribe Anderson Imbert (1992, p. 25) que "[1]a breve unidad de un cuento consiste en que los hilos de acción narrada se urden en una trama; y todas las tramas pueden reducirse a un número limitado de conflictos.[...] Yo 1[o]s reduciría a un[o]: [el] de la voluntad que choca con algo que le resiste". Si se aceptan estas observaciones, se deduce que el objeto principal 


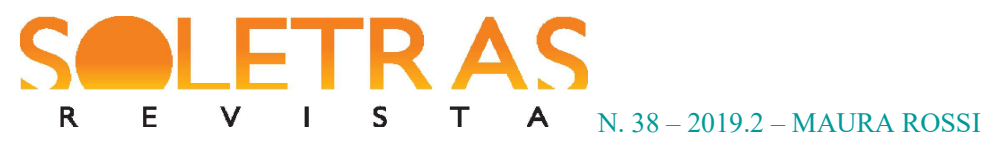

de un relato es algún tipo de contraste abierto entre fuerzas opuestas, que precisa algún tipo solución dentro de la extensión limitada que ofrece el género.

Ahora bien, analizando Los Girasoles Ciegos se nota ante todo que los cuatro cuentos empiezan todos con el establecimiento de un conflicto entre la vida y la muerte, es decir con un desajuste, casi un oxímoron entre las condiciones vitales del cuerpo y las aspiraciones del alma, padecido de formas diferentes por los varios personajes centrales y que siempre acaba acarreando una fuerte tensión entre la supervivencia y la extinción, convirtiéndose en el núcleo temático de cada derrota. En efecto, se observa que cada narración se abre in medias res y que las anécdotas previas que el lector precisa para poder entender las circunstancias que provocaron el conflicto de voluntades quedan recuperadas de forma 'taquigráfica' a continuación. Es más, los primeros párrafos de cada cuento se configuran como una síntesis de los factores previos que desencadenaron el episodio inicial y, al mismo tiempo, marcan un viraje sustancial en el flujo de los eventos narrados.

El primer relato y el tercero son posiblemente a los que se ajustan de manera más transparente las observaciones que se acaba de formular. De hecho, el episodio que abre la "Tercera derrota" no es sencillamente uno más de los varios interrogatorios a los que Juan Senra es sometido durante sus dos años de permanencia en la cárcel, sino que coincide con el momento en que queda pronunciada la respuesta afirmativa que constituye el motor de toda la narración: “Con la turbación con que se pronuncia un sortilegio Juan Senra, profesor de chelo, dijo sí y, sin saberlo, salvó momentáneamente su vida” (MÉNDEZ, 2008, p. 61). Desde las primeras líneas el lector llega a conocer un personaje, artista y no soldado, cuya supervivencia solo resulta garantizada temporalmente gracias a un 'sí' cuyos efectos salvíficos son inicialmente ignorados. Quedan revelados de inmediato y de manera "sucint[a]", que decía Méndez, los ejes temáticos que rigen el relato, es decir una condena de muerte pendiente, no evitada, sino probablemente tan solo aplazada, y un medio de supervivencia que coincide con una afirmación cuyo referente es el hijo del coronel que está juzgando a Juan, con el que el preso coincidió durante la guerra en la cárcel madrileña de Poriler (MÉNDEZ, 2008,p. 61). Análogamente, la "Primera derrota" se abre con el grito reiterado "iSoy un rendido!" y con la entrega por parte del Capitán Alegría de su propia persona a unos soldados republicanos “incrédulos" (MÉNDEZ, 2008, p. 13) que saben que la ocupación de la capital por parte del ejército franquista es una mera cuestión de horas. El agotamiento vital y anímico del que brota esta decisión meditada de cruzar la trinchera con vistas a la victoria del ejército nacional 


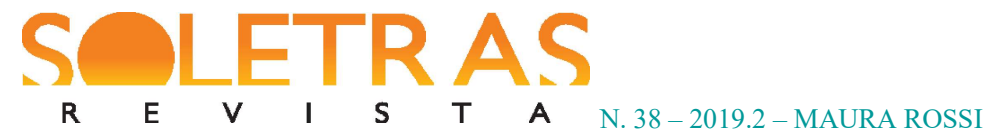

queda inmediatamente explicitado en la medida en que el personaje, significativamente presentado a partir de su grado militar, lleva a cabo su gesto con la esperanza de ser ajusticiado: "Ahora sabemos que el capitán Alegría eligió su propia muerte a ciegas, sin mirar el rostro furibundo del futuro que aguarda a las vidas trazadas al contrario" (MÉNDEZ, 2008, p.13). En cambio, justamente las secuelas imprevistas de su rendición "más existencial, humana, que bélica" (MAUREL, 2004, p. 271) rigen el esqueleto narrativo del cuento, como en el caso de la respuesta afirmativa de la "Tercera derrota".

Más articulada resulta la interpretación del comienzo de la "Segunda derrota", que empieza con la voz del personaje-transcriptor que, en principio, adelanta la información crucial relativa a la muerte del autor del diario "en 1940 en una braña de los altos de Somiedo" (MÉNDEZ, 2008, p. 39). Se delinean, entonces, dos recorridos ficcionales estrechamente ligados e interdependientes, el primero vinculado con la escueta declaración de intenciones del 'editor', el segundo coincidente con la narración contenida en el autógrafo, eso es, con la historia de un joven poeta fugado de la capital, que en las montañas inhospitalarias de Asturias lucha por la supervivencia suya y de su hijo nacido durante la huida. Ahora bien, la intervención del editor resulta fundamental para la percepción que el lector tiene del cuaderno: no solo este personaje, parafraseando el título de la derrota saca el manuscrito del olvido, sino que también le impone un ritmo por medio de la enumeración progresiva de las hojas, $\mathrm{y}$, como ya se ha dicho, lo interpreta proporcionando descripciones iconográficas e interpretaciones acerca de elementos tanto textuales como paratextuales (tachaduras, características gráficas de la letra, dibujos que el poeta alterna con las palabras, reflexiones sobre el instrumento utilizado para escribir, y, sobre todo, huecos o pausas encontradas en el texto). Pese a esta consistente intervención, la voz del poeta y no la del narrador es la que prevalece en la "Segunda derrota", tanto que se tiende a olvidar la advertencia que se ha recibido al principio -"se encontraron un esqueleto adulto y el cuerpo desnudo de un niño de pecho [...] juntos y envueltos en una colcha blanca" (MÉNDEZ, 2008, p. 39). En el contexto del diario, ya en la primera entrada se patentiza un ejemplo extremo de convivencia contrastiva entre la vida y la muerte, ya que se da noticia de una madre fallecida durante un parto, ya que en una etapa indefinida de un intento de huida "a Francia" la mujer de quien escribe "ha muerto durante el parto [y] sorprendentemente el niño está vivo. [...] Yo no sé qué hacer. No me atrevo a tocarlo. [...] Ya no huiremos [...]. Sin Elena no quiero llegar hasta el fin del camino. Sin Elena no hay camino" (MÉNDEZ, 2008, p.40). 


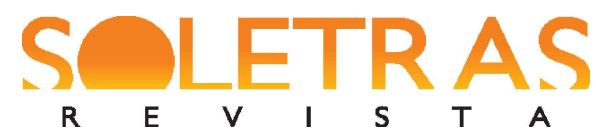

El análisis del "planteamiento sucinto" de la "Cuarta derrota" también resulta controvertido, si se considera que en páginas que la componen alternan tres ejes temporales y tres voces distintas. Los dos fragmentos que abren el relato quedan atribuidos con este mismo orden al hermano Salvador y a Lorenzo Mazo, cuyas versiones parciales en un primer momento resultan percibidas como sugestiones esparcidas por el lector todavía no familiarizado con el mecanismo narrativo del cuento. La primera sección sobre la base de la que el lector adquiere cierta orientación limitadamente al juego de relaciones que el autor establece entre las tres diferentes versiones es la tercera, en la que no solo convergen las referencias de los dos narradores precedentes -de modo que el lector logra contextualizarlas-, sino que también quedan rellenados algunos de los huecos presentes en los testimonios particulares de éstos. Estando así las cosas, el primer fragmento atribuido al narrador en tercera persona recrea el retrato de una familia amorosa y unida -la que había mencionado Lorenzo Mazo en sus recuerdos trabados-que presenta dos peculiaridades: un niño que no quiere ir al colegio porque el cura de la carta inicial,"el hermano Salvador[,] le tiene manía”, y un padre que durante la etapa republicana fue profesor de literatura de secundaria, cuya presencia debe mantenerse secreta - “‘ ¿y tú qué le respondes cuando te pregunta por mí?’ 'Que estás muerto"” (MÉNDEZ, 2008, p. 110).

Símilmente, si los cuatro cuentos parecen coincidir en su comienzo estructurado según un planteamiento esencial de la acción, cargado de tensión y 'conflictivo', también se aprecia en el conjunto de derrotas el armazón de un "enredo esquemático" (MÉNDEZ, 2004) cuyo meollo son las condiciones vitales y anímicas sufridas por el capitán Alegría, el joven poeta fugitivo, Juan Senra y, finalmente, Ricardo Mazo.

Es posible observar que al principio de cada derrota los cuatro personajes se encuentran en un estado diferenciado de muerte en vida, identificado con un fuerte agotamiento físico o anímico que provoca, como ya se ha recordado, una discrepancia desgarradora entre las condiciones del cuerpo y las voluntades de la mente. Como se verá, la muerte es la perspectiva dominante para todos los personajes al principio de cada cuento, no obstante, conforme avanza el relato parece insinuarse cierta posibilidad de supervivencia, acogida o rechazada, consistente o débil, fundada en esperanzas plausibles o desesperada. El momento en que, pese a todo planteamiento inicial, el contexto de muerte se abre parcialmente a la vida constituye, podría decirse, el vértice de un movimiento que con vistas a los pasajes sucesivos podría definirse 'parabólico', en la medida en que, tas un clímax que 


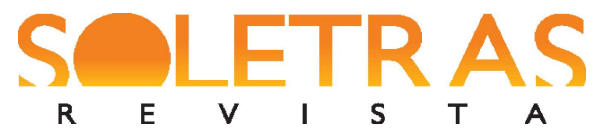

N. $38-2019.2$ - MAURA ROSSI

casi se convierte en espejismo, queda representada una inflexión que cabría definir descendiente, y que coincide con el anonadamiento definitivo de los personajes representados, para acabar en última instancia con la frustración total de cualquier impulso vital. Pese al recorrido de tipo 'parabólico' que se acaba de perfilar, sin embargo, también puede individuarse en cada cuento una suerte de progresión 'lineal' que lleva directamente, desde el comienzo, hacia el desenlace dramático de las derrotas y que atraviesa la parábola sutil e inexorablemente, contradiciendo de manera patente cualquier esperanza de vida.

Para empezar, en el comienzo de la "Primera derrota" Carlos Alegría queda descrito como un hombre deshecho por tres años de guerra de desgaste, y su cansancio existencial se traduce en la voluntad meditada de cerrar la cuenta con su propio sentido de la justicia entregándose a un enemigo que está a punto de ser vencido y entonces, verosímilmente, va a perder todo tipo de jurisdicción sobre el adversario. Alegría es oficial del ejército sublevado y conoce el tratamiento que se reserva en tiempos de guerra a quien se rinde a los enemigos; es más, justamente por haber militado entre los fieles a Franco y por estar familiarizado con su política de aplastamiento incondicional de toda oposición, tanto interna como externa, sabe que los vencedores no otorgarán ninguna clemencia a quienes sean juzgados "traidor[es]" (MÉNDEZ, 2008, p.23). La muerte del cuerpo que Alegría va buscando al aproximarse a la trinchera opuesta no marcaría sino el reflejo biológico de un inexorable y progresivo proceso de apagamiento mental y emotivo que ha ido anidándose en el personaje a lo largo de la guerra. A este propósito, obsérvese que el capitán no se rinde al enemigo, sino que manifiesta frente a él su condición psicológica de rendido: la diferencia de significado es sustancial en este punto, ya que la frase “"me rindo' [...] respondería a algo congelado en un instante cuando la verdad es que él se había ido rindiendo poco a poco" (MÉNDEZ, 2008, p.13) ${ }^{17}$. Tras entregarse y ser juzgado por sus antiguos compañeros de armas, Alegría aguarda su ejecución en un aeródromo de Barajas donde los nacionales celebran "juicios sumarísimos que acabaron, sin excepción, en condenas a muerte” (MÉNDEZ, 2008, p. 25). El narrador supone que surgiera en él "cierto alivio cuando el día dieciocho [...] fue él uno de los miembros de la recua", sin embargo, ni los disparos del pelotón ni la sepultura de su cuerpo herido logran acabar con su supervivencia. Alegría despierta, en vida, dentro de una fosa

\footnotetext{
${ }^{17}$ Reflejan este estado de ánimo algunos escritos autógrafos del capitán, tanto personales como profesionales, en los que se lee que "la violencia y el dolor, la rabia y la debilidad, se amalgaman con el tiempo en una religión de supervivencias, en un ritual de esperas donde entonan la misma salmodia el que mata y el que muere, la víctima y su verdugo" y que "todo cuadra cabalmente con los estadillos adjuntos, menos el oficial que esto firma, que se considera a sí mismo un círculo cuadrado, un espíritu metálico” (MÉNDEZ, 2008, p.14 y 22).
} 


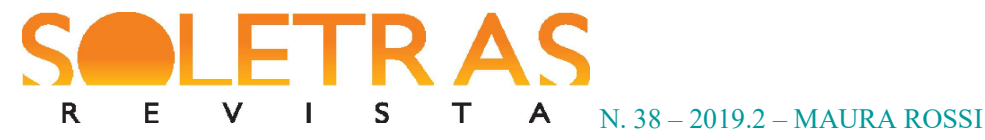

común cavada de manera demasiado apresurada como para que le resulte imposible salir de ella; es más, aun frente a la perspectiva casi descontada de la muerte, su cuerpo logra mantenerse vivo gracias a un instinto de supervivencia que nada tiene que ver con las esperanzas o con los planes del capitán, sino que se resuelve en un mero impulso físico que no hace sino obstaculizar la voluntad anímica de muerte. En esta dirección interpretativa cabe orientar, posiblemente, la lectura del título que abre el cuento junto a la fórmula "Primera derrota: 1939": de hecho, en el sintagma "si el corazón pensara dejaría de latir" (MÉNDEZ, 2008, p. 11), el corazón ya no queda identificado, pese a serlo a menudo en las estilizaciones literarias e incluso culturales, como la objetivación de la interioridad, sino que resulta ser un mero músculo involuntario cuya tendencia natural hacia el funcionamiento a ultranza contrasta con el deseo de acabamiento que manifiestan los pensamientos. Debido a ese corazón obstinado, que, por el hecho de que no piensa, no conoce la condición de usura vital que acosa al capitán, tiene lugar el "segundo nacimiento" de Alegría -tal y como lo define su protagonista- una elección no conforme, que sin embargo lo fuerza a alejarse, aunque solo sea físicamente, del proyecto de muerte puesto en marcha a principios de la derrota. Varios gestos que van desde el cuidado misericordioso de un grupo de campesinos hasta los tratamientos que le suministran en las enfermerías de "las prisiones donde estuvo más tarde" (MÉNDEZ, 2008, p. 33) hacen que el cuerpo de Alegría no solo vuelva a cobrar fuerzas vitales, sino que hasta alcance a hacerse coriáceo e insensible ante el dolor: así, pues, se presenta el personaje cuando el lector vuelve a encontrarlo en la cárcel de la "Tercera derrota" tras haberlo dejado desmadejado y febricitante al final de la "Primera"18. El tercer cuento proporciona una descripción detallada del punto final de la parábola de Alegría, cuando el capitán logra por fin adecuar sus condiciones corporales a su estado existencial y se arrebata la vida volándose los sesos con un fusil sustraído a unacentinela en la cárcel madrileña donde se encuentra detenido ${ }^{19}$.

En lo que atañe al elemento lineal que permitiría trazar una conexión directa entre el deseo inicial de muerte y el alcance final de dicho objetivo, quizás resulte posible identificarlo

\footnotetext{
${ }^{18}$ Se lee en la "Tercera derrota" que "se acercaron dos soldados que con las culatas de sus fusiles trataron de apartarle de la puerta. Pero su capacidad de sentir el dolor se había agotado tiempo atrás ante un apresurado pelotón de fusilamiento y la contundencia de los culatazos no parecía afectarle" (MÉNDEZ, 2008, p. 89).

${ }^{19} \mathrm{La}$ información relativa al suicidio del capitán también quedaba presentada a finales de la "Primera derrota", pero de forma mucho más escueta, pues el narrador se limitaba a comentar de paso que "debió de ser entonces cuando nació la reflexión que recogió en unas notas encontradas en su bolsillo el día de su segunda muerte, la real, que tuvo lugar más tarde, cuando se levantó la tapa de la vida con un fusil arrebatado a sus guardianes" (MÉNDEZ, 2008, p. 35).
} 


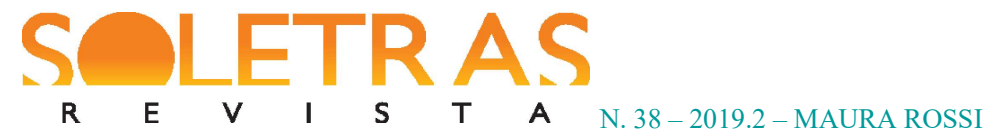

con la descripción física del capitán que el narrador proporciona a partir del episodio de su fusilamiento. De hecho, desde que sale de la fosa común Alegría se convierte en un retrato vivo de la muerte, en la medida en que su cuerpo débil y ensangrentado cobra paulatinamente el aspecto, el olor y el color de un cadáver: en la "Primera derrota" esta superposición gradual de imágenes pasa antes por el error de percepción de los campesinos que socorren a Alegría, los cuales en un primer momento "le creyeron muerto [y] decidieron descalzarle para hacerse con las botas del cadáver", y luego por la observación que durante la marcha desesperada que el capitán intenta emprender para morir en su pueblo natal "los lobos y [...] los perros asilvestrados [...] merodeaban pacientes esperando el final de aquel peregrinaje" (MÉNDEZ, 2008, p. 32-35). Dicha connotación alcanza su cumbre en la "Tercera derrota", donde Alegría queda retratado como un hombre "tatuado por la muerte" ${ }^{20}$ que presenta "unos enormes ojos que no parpade[an], como si estuvieran en un estado de estupor perpetuo" (MÉNDEZ, 2008, p. 89 y 87).

De modo contrario con respecto a la "Primera derrota", la segunda se abre con una muerte del cuerpo, que se acompaña a modo de oxímoron a un nacimiento. El fallecimiento de Elena, mujer del poeta que redacta el diario, no queda presentado como un reflejo de las desganas de vivir de la joven, sino más bien como una capitulación - una 'rendición' si se quiere- de sus fuerzas físicas mermadas por los rigores de una marcha que se suponía salvadora. Esa muerte prematura que marca el principio de la derrota contagia de inmediato al poeta con su rigidez "heladora" y con su olor penetrante (MÉNDEZ, 2008, p. 42): el joven, anonadado por el abandono inesperado de su compañera de viaje, rechaza toda perspectiva de supervivencia y decide que la cabaña donde la perdió será el lugar de sepultura suyo y de su hijo. Por esa razón, se niega a alimentarse pese a guardaren su fardo "un poco de pan seco y unas conservas de pescado" (MÉNDEZ, 2008, p. 45) y, sobre todo, decide no tocar al recién nacido y abandonarlo envuelto en "la placenta que le rodea" al lado del cuerpo macilento de su madre. Una vez más, sin embargo, fracasa el proyecto inicial de muerte y "la vida se [...] impone a toda costa" (MÉNDEZ, 2008, p. 44): el niño llora repetidamente, hasta que consigue que su padre despierte del torpor existencial en que ha caído y lo alimente, lo limpie y le dé calor con su cuerpo. Estos gestos inicialmente mecánicos, desganados, que el poeta

\footnotetext{
${ }^{20}$ Se alude aquí a la cicatriz que "desperdiga [el] pelo [de Alegría] en dos mitades" y que se debe a la bala que durante el fusilamiento no logra centrar su cabeza, sino que se limita a rozarle la coronilla manteniéndolo con vida (MÉNDEZ, 2008, p. 87).
} 


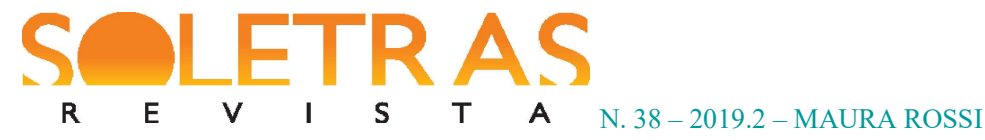

realiza “impensadamente” (MÉNDEZ, 2008, p. 43) ${ }^{21}$, desencadenan un instinto de supervivencia que va más allá de la pulsión de muerte y convierte la estancia forzosa en la montañas en una lucha por seguir viviendo. El joven expresa en varias hojas de su diario la certeza, que se hace más firme conforme avanza el invierno, de que ni el niño ni él lograrán ver la primavera sucesiva ${ }^{22}$; sin embargo, se ingenia para cuidar al bebé, busca raíces e intenta hervir caldos que sustituyan la leche maternal, construye un camastro abrigado y entona canciones de cuna, logra acorralar un par de vacas para que proporcionen alimento y calor, según una destartalada reelaboración del motivo belenita. La pasividad inicial que lo había llevado a escribir “el niño no vivirá y yo me dejaré caer en los pastos” (MÉNDEZ, 2008, p. 42-43) hasta llega a quedar remplazada por manifestaciones detonantes de vida -“¡Hoy he matado un lobo! Me lo comeré y utilizaré sus entrañas para hacer algo comestible para el niño" (MÉNDEZ, 2008, p.50) -, que sin embargo chocan violentamente con la imposibilidad material de "desentrañar la nieve silenciosa" y conseguir sustentamiento - "si pudiera descendería al valle para pedir comida, pero es imposible salir de estas montañas” (MÉNDEZ, 2008, p. 53). Se vuelve a perfilar, pues, una falta de correspondencia entre la supervivencia física y la espiritual: en esta ocasión, la mente tiende a atender la llamada de la vida, resiste de alguna manera a los horrores del exilio trabado e impone momentáneamente su impulso para seguir adelante; el cuerpo, sin embargo, debilitado por el frío y el hambre, no logra secundar estos instintos. A consecuencia, pese a que en algunas hojas del diario se registren momentos de precaria estabilidad vital - "tenemos carne suficiente con la vaca muerta [...]. Afortunadamente disponemos de leche abundante gracias a la vaca viva, que ahora comparte con nosotros el refugio y nos da calor" (MÉNDEZ, 2008, p.47) - la débil ilusión de vida deja lugar pronto a la desnutrición, a la enfermedad y, finalmente, al fallecimiento, antes del niño, luego del poeta.

\footnotetext{
${ }^{21}$ Compárense las acciones que se acaba de citar, que podrían decirse incontroladas, con el latido involuntario del corazón de Alegría.

${ }^{22}$ Véanse los siguientes pasajes: "Quiero dejar todo escrito para explicar a quien nos encuentre que él también es culpable, a no ser que sea otra víctima. Quien lea lo que escribo, por favor, que esparza nuestros restos por el monte" (MÉNDEZ, 2008, 41, hoja 3 del diario); "pronto se cerrarán todos los caminos de acceso a esta braña. Tendré todo el invierno para decidir de qué muerte moriremos" (MÉNDEZ, 2008, p. 47, hoja 9); "solo me preocupa el lápiz. Tengo uno y quisiera escribir lo necesario para que quien nos encuentre en primavera sepa qué muertos ha encontrado" (MÉNDEZ, 2008, 47, hoja 10); "si sigo aquí moriremos la vaca, el niño y yo. Si descendemos al valle moriremos la vaca, el niño y yo" (MÉNDEZ, 2008, 52, hoja 17); "el miedo, el frío, el hambre, la rabia y la soledad desalojan la ternura. Solo regresa como un cuervo cuando olisquea el amor y la muerte. Y ahora ha regresado confundida. Olfatea ambas cosas" (MÉNDEZ, 2008,55, hoja 20).
} 


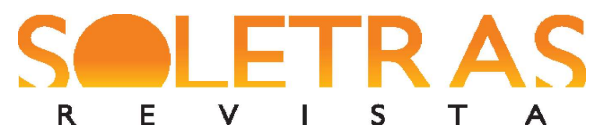

N. $38-2019.2$ - MAURA ROSSI

Este itinerario inexorable y, como se ha argumentado, parabólico-desde la muerte hasta la vida, y luego de vuelta de la vida hacia la muerte- queda atravesado por un elemento que, partiendo de las desesperadas condiciones iniciales, se dirige de manera tajante y directa hacia el destino final de extinción. Se trata de la escritura del poeta, que cobra dos distintas significaciones dentro de la economía de la derrota y que, conforme pasa el tiempo, se hace más pequeña y transparente, al igual que el cuerpo de Alegría. Por un lado, la identificación entre el acto de redactar y la vida misma del joven es total, ya que el persistir de la escritura es índice de la perseverancia de alguna fuerza física y psicológica ${ }^{23}$; por el otro, el tamaño y la forma de la letra reflejan un creciente agotamiento psico-físico, que hacia las últimas páginas se convierte en una debilidad total del cuerpo que acarrea para la mente del poeta un estado muy parecido a la locura. De hecho, inicialmente la "caligrafía [es] meliflua y ordenada,[...] de mayor tamaño", pero en la hoja 12 comenta el editor que los trazos se hacen "más apresurados, [aunque la pulcritud de la escritura se mantiene]. Probablemente ha trascurrido bastante tiempo" (MÉNDEZ, 2008, 39 y 50). La letra de las últimas hojas es extremadamente diminuta, la escritura febril: el poeta no hace sino repetir en series infinitas el nombre "Rafael" -otro "lugar [...] de memoria" según la lectura de Cruz Suárez (2015, p. 103)-, que ha escogido para su hijo después de que éste falleciera. Las últimas palabras casi no pueden leerse debido a que ya no van escritas en lápiz, sino "con un tizón apagado o algo parecido" (MÉNDEZ, 2008, p.56).Tal como su instrumento de escritura, las resistencias del joven se han ido reduciendo hasta apagarse totalmente: fenece el diario y, junto a él, se extingue el poeta.

Como ya se ha comentado, el enredo de la "Tercera derrota" se abre con una condena a muerte pendiente, cuya pronunciación definitiva no parece depender del resultado del proceso al que el reo está sometido, sino que queda presentada comouna cuestión de tiempo. Tras dos años en la cárcel, Juan Senra conoce a la perfección el funcionamiento del mecanismo de muerte que la rige: sabe que casi nadie logra escabullirse de la ejecución y, al mismo tiempo, que existen estratagemas que permiten aplazar durante un tiempo variable las sentencias del tribunal militar, otorgando a los presos semanas e incluso meses de vida arrebatada a la muerte. La larga rutina de interrogatorios, palizas, privación y convocaciones de compañeros de reclusión ante el pelotón hace que Senra viva una condición de

\footnotetext{
${ }^{23}$ Apunta el autor del diario que tiene "la sensación de que todo terminará cuando se me termine el cuaderno. Por eso escribo solo de tarde en tarde" (MÉNDEZ, 2008, p. 56). Las cuartillas numeradas son 26 en total.
} 


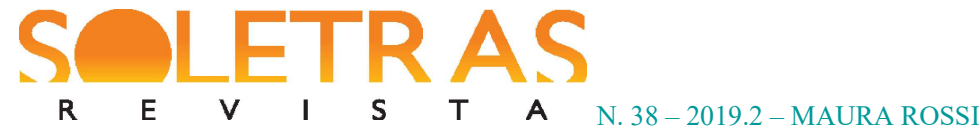

apagamiento emotivo y agotamiento psicológico que lo lleva a percibirse a sí mismo como un muerto andando, al igual que Alegría: la muerte interior de Juan Senra y su 'anestesia mental' se deben a la arbitrariedad y crueldad con los que intencionalmente los carceleros manejan las vidas de los presos. Inicialmente, lo único que mantiene en vida su cuerpo es el rancho desabrido que le suministran, junto a los recuerdos de su vida antes de la cárcel, cuya monotonía alienante queda rota por dos encuentros que tienen lugar el mismo día. El primero es con un muchacho de Brunete, alojado en la misma celda de Juan e infestado de piojos: al conversar con el joven, el profesor de chelo recuerda a su hermano y, aun no queriéndolo, se abandona al lento nacimiento de una amistad fraternal que vuelve a despertar en él sentimientos humanos olvidados bajo capas espesas de miedo y sufrimiento ${ }^{24}$. El segundo encuentro es con la mujer del coronel Eymar cuya sed de detalles es inmediatamente olfateada por el preso, que al mismo tiempo comprende que proporcionárselos 'a plazos' quizá tenga el efecto "como a Sherezade, [de otorgarle] una noche más. Y otra noche más. Y otra noche más" (MÉNDEZ, 2008, p.97). Por medio de los dos encuentros, ambos inesperados, el redescubrimiento de instintos perdidos de vida se apareja de inmediato a la posibilidad concreta de seguir existiendo gracias a la mentira: aquí tiene su comienzo el trecho ascendiente de la parábola, pues Juan abandona lentamente y de manera desavisada mucha parte de su resignación a la muerte y vuelve a confiar en su posible supervivencia. Al principio Senra solo se atreve a persuadirse de que está sustrayendo a la ejecución un tiempo bastante limitado, sin embargo conforme aumenta la intimidad con el muchacho de las liendres y conforme circulan en la cárcel noticias animadoras procedentes del exterior, el débil instinto de Juan se convierte en una suerte de rebelión anímica en contra del fusilamiento, que hasta lleva el preso a suponer que morir ajusticiado ya no es una opción ${ }^{25}$ :

\footnotetext{
${ }^{24}$ Se señala que a partir de este primer encuentro siempre que Juan aparezca en el texto junto al joven de los piojos vuelve a mencionarse el motivo de la hermandad, tanto bajo la forma de la carta que Senra redacta para su hermano mientras habla con el muchacho, como por medio de los recuerdos que el preso intenta recuperar.

25“"Les digo lo menos posible para ver si me dejan vivir unos días más.[...] El día que me descubran yo también iré a la cuarta, no te apures" contesta Juan a las preguntas de un compañero de celda sospechoso, que reconoce como anomalía el hecho de que tras varios interrogatorios el profesor siga siendo devuelto a la segunda galería, donde "esperaban los que iban a ser condenados a muerte", y no resulte en cambio destinado a la cuarta, donde "contaban los minutos quienes ya habían sido condenados" (MÉNDEZ, 2008, p. 80 y 66). Y más adelante, sabían por el alférez capellán que no todos los condenados a muerte eran ya fusilados. Intervenciones de familiares, recomendaciones especiales, gestos arbitrarios de gracia iban reduciendo el número de ejecutados a medida que pasaban los meses.[...] Por eso solo pensaban en que pasara el tiempo, que discurriera todo lo lenta y brutalmente que quisiera, pero que hubiera una semana más, un día más, incluso una hora más"; "comenzaron a llegar noticias lenitivas de aquel silencio. Hitler estaba bloqueado en la batalla de Inglaterra, los maquis se organizaban en varias zonas del norte y se rumoreaba que los Estados Unidos iban a invadir la península por el
} 


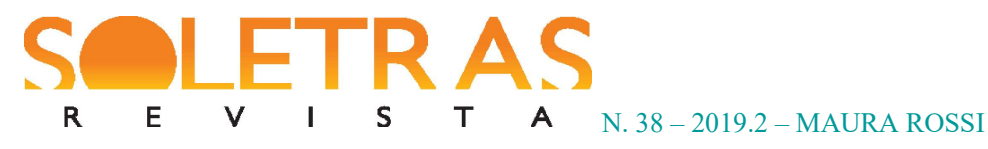

¿Muerte? ¿Por qué muerte? Todavía nadie le había acusado de algo concreto que no fuera haber vivido en Madrid durante la guerra. Nadie sabía que había llegado desde Elda comisionado por Fernando Claudín para organizar un atentado contra el coronel Casado.[...] Era demasiado joven, demasiado oscuro para atribuirle cualquier responsabilidad en la guerra. Y esto le consolaba. Podía ser simplemente un derrotado más, un perdedor fortuito porque fortuitamente estaba en Madrid el 18 de julio de 1936. Quizás lograra ocultar la derrota de Juan Senra. (MÉNDEZ, 2008, p.90-91)

No obstante, estas llamadas de vida en un primer momento atendidas chocan de repente contra un acontecimiento que tiene el efecto de desmoronar el frágil equilibrio de esperanzas alcanzado por Juan: tras escuchar el nombre del muchacho de las liendres entre los convocados para someterse al pelotón, Senra se abandona totalmente a la anulación de su espíritu y rechaza cualquier apego a una supervivencia tomada a préstamo de una muerte ya establecida. Por consiguiente, haciendo acopio de sus últimas fuerzas, interrumpe de manera abrupta la mentira que lo mantenía en vida y así sanciona imperiosamente su condena definitiva.

Aun así, al igual que en la "Primera derrota" y en la segunda, también en la tercera se ha creído notar un elemento que acompaña paulatina y directamente al lector hacia la conclusión del cuento. Se trata, en este caso, del críptico lenguaje que Senra cree escuchar en sus sueños y entresueños y que al principio no logra identificar, pese a sentirse de alguna manera 'acogido' respectivamente en él. Senra describe el lenguaje en numerosas cartas que redacta "hacia" su hermano ${ }^{26}$, y que le quedan constantemente devueltas llenas de tachaduras: en una de las primeras escribe "sueño constantemente sin saber si estoy dormido, y me imagino sin querer un mundo casi vacío en el que todos hablan un idioma extraño que no entiendo aunque no me siento forastero" (MÉNDEZ, 2008, p. 84); conforme pasa el tiempo, esa lengua enigmática se hace "cada vez más asequible” (MÉNDEZ, 2008, p. 94) y cobra la forma de una serie de neologismos que traducen sensaciones y acciones que solo encuentran

sur. Todos deseaban pasar tiempo y aprendieron que ritmando los segundos transcurriría un minuto cada vez que se contaban sesenta" (MÉNDEZ, 2008, p. 68 y 86-87).

${ }^{26}$ Según una identificación de la escritura con la vida similar a la que se ha encontrado en la "Segunda derrota", Senra mismo reconoce que "mientras pueda escribirte es que aún estoy vivo" (MÉNDEZ, 2008, p. 79) y abre cada párrafo de su misiva escrita a plazos entre una convocación ante el tribunal y otra con la expresión "sigo vivo", que se convierte, en cambio, en una suerte de letanía anticipadora de la muerte (MÉNDEZ, 2008, p. 84, $86,94$ y 98$)$. 


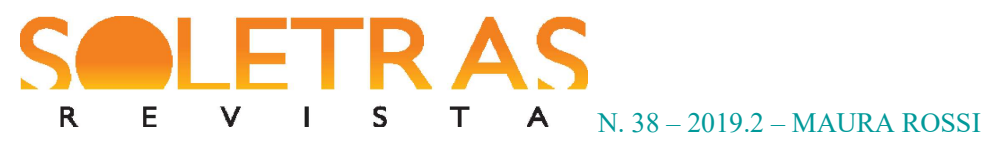

cabida dentro del limbo de la cárcel y por lo tanto no tienen nombre en el mundo externo de los vivos:

Hablo de amortesía cuando quiero demostrar afectos y suavumbre es la rara cualidad de los que me hablan con ternura. Colinura, desperpecho, soñaltivo, alticovar son palabras que utilizan las gentes de mis sueños para hablarme de paisajes añorados y de lugares que están más allá de las barreras. Llaman quezbel a todo lo que tañe y lobisidio al ulular del viento. Dicen fragonantía para hablar del ruido del agua en los arroyos. Me gusta ese idioma. (MÉNDEZ, 2008, p. 94)

Solo hacia el final, cuando ya se ha resuelto a dejar de vivir, Senra llega a descifrar el habla oculta de su inconsciente y anota que ha "descubierto que el idioma que he soñado para inventar un mundo más amable es, en realidad, el lenguaje de los muertos" (MÉNDEZ, 2008, p. 98$)^{27}$, un indicio desde el principio sumía gradualmente al preso dentro de la comunidad de los difuntos.

El enredo de la "Cuarta derrota" se articula principalmente alrededor de Ricardo Mazo, aunque, debido a la circunstancia del 'exilio' forzoso dentro de su propia casa, se trate del personaje que menos deja percibir su voz en la derrota. Ricardo vive no emboscado, como los disidentes del maquis, sino 'empotrado', ya que un armario ocultado en la pared de su dormitorio le sirve tanto de refugio cuando en casa acuden personas que no son su mujer e hijo, como de depósito de traducciones y libros que al estar colocados en las estanterías de la vivienda delatarían la presencia en su interior de una ideología liberal no conforme con la dominante. Al principio de la derrota Ricardo queda descrito como un hombre cuyas palabras son más propiamente susurros y cuyos pasos casi no se pueden percibir, como si flotara en el aire: su condición le obliga a "vivir como si no existier[a]" (MÉNDEZ, 2008, p. 128), no obstante sigue ocupando cierto lugar tanto física como espiritualmente dentro del reducido núcleo familiar: se preocupa por la educación de su hijo, sigue cultivando cierto interés por la literatura y contribuye ocultamente al sustentamiento de su familia con trabajos mecanografiados que su mujer vende por suyos. Sin embargo, conforme transcurren los meses y el interés del hermano Salvador hacia Lorenzo y Elena se traduce en obsesión, Ricardo pierde la esperanza de salir de su escondite en tiempos razonables, con lo cual se hace cada

\footnotetext{
${ }^{27}$ Se trata de una reproducción casi literal del título de la derrota.
} 


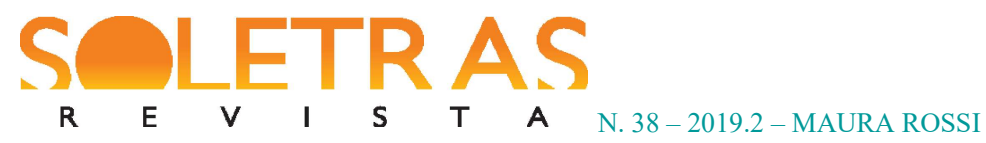

día más ensimismado, pasivo y temeroso. Es para evitar una degeneración de su depresión que Elena cede al proyecto inicialmente rechazado de una huida hacia Marruecos y empieza a vender "todo lo que pueda" con vistas a pagar los pasajes para los "pesqueros que pasan fugitivos de Almería” (MÉNDEZ, 2008, p.147). La perspectiva de supervivencia que se ha identificado en las demás derrotas con el vértice de la parábola vital de los personajes centrales resulta aquí netamente débil, ya que no llega a alcanzar más que el estado de mero proyecto. De hecho, en el piso ya despojado de todo mueble se avalancha el hermano Salvador "vestido de seglar" e intenta arremeter contra "el templo bien guardado" de Elena (MÉNDEZ, 2008, p.151-52); Ricardo sale del armario para defender a su mujer y, delatándose, decreta la conclusión de una existencia que para él ya hacía tiempo que carecía de sentido.

Si se intenta trazar para este cuento un trayecto lineal que guíe al lector directamente hacia la muerte no solo anímica, sino también física de Ricardo, probablemente convenga identificarlo con la comparación progresiva que viene delineándose entre el personaje y diferentes seres de la ultratumba. De hecho, desde el principio el profesor queda descrito como una presencia ectoplasmática debido a que no produce ruidos, pero está presente; al igual que el "aire, est[á], pero no ocupa lugar en el espacio", como un fantasma se esconde en un armario y aparece solo en la oscuridad o en la sombra "con un sigilo que, en ocasiones, [consigue] asustar a su mujer y a su hijo" (MÉNDEZ, 2008, p. 142 y 114) ${ }^{28}$. El segundo medio de comparación invocado del mundo de los entremuertos resulta aún más expresivo para representar el estado de Ricardo y coincide con unos "leprosos" -o zombis-protagonistas de los cuentos de terror con los que un niño mayor asusta al grupo formado por Lorenzo y sus amiguitos. Los leprosos son seres que se mueven "lenta e imparablemente" y padecen una enfermedad que, al igual que la depresión de Ricardo, no es "infecciosa, [sino que es] una enfermedad del alma, y su peligro no estiba en el contagio, sino en su voracidad caníbal" (MÉNDEZ, 2008, p.131). Lorenzo empieza a encontrar correspondencias entres los leprosos y su padre cuando reconoce en el armario el mismo olor del Metro de Madrid, que en su

\footnotetext{
${ }^{28}$ Esta identificación se hace total en el episodio en que queda descrita una de las meriendas que Elena ofrece de manera planificada y regular a los amigos de Lorenzo con tal de no tener visitas inesperadas que acabarían desencadenando los "mecanismos de fuga sin huida" aprontados por la familia en el caso de que alguien toque al timbre (MÉNDEZ, 2008, p. 151). Durante una de estas ocasiones Ricardo precisa correr al baño por sentirse enfermo y los niños se asustan al ver por el cristal de la ventana de la cocina una silueta que, por lo que saben, no debería corresponder a la presencia de otro adulto en la casa además de Elena. Recuerda Lorenzo que "para salir de paso, mi madre resolvió la situación hablando de un fantasma que de vez en cuando venía a visitarnos" (MÉNDEZ, 2008, p.134).
} 


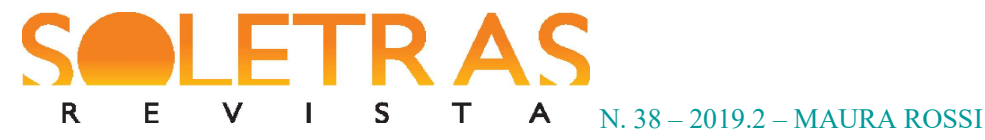

imaginación de niño es el lugar donde los zombis residen en espera de atacar a los humanos: a estas alturas el escondite de Ricardo ya se ha convertido en una suerte de ataúd del que el hombre "empequeñeci[do] y desaseado" apenas sale (MÉNDEZ, 2008, p. 132) ${ }^{29}$. Como en el caso del fantasma, también la comparación entre Ricardo y un zombi se convierte en identificación total cuando, hacia finales de la derrota, Lorenzo invoca a los leprosos para que salven a su madre del acoso sexual del fraile y, sin embargo, quien aparece a librarla del peso del hermano Salvador es su padre: confiesa Lorenzo adulto que

durante muchos años me ha atormentado el remordimiento por haber invocado a los leprosos para que se comieran a ese energúmeno que estaba haciendo daño a mi madre, porque cuando acudí aterrorizado al oír sus gritos vi como mi padre, desangelado e impotente, se abalanzaba sobre el hermano Salvador que estaba a horcajadas sobre ella. (MÉNDEZ, 2008, p. 152)

A partir de los argumentos que se han formulado arriba podría concluirse que el desenlace de cada cuento, es decir el momento en que se perfila la solución definitiva de la tensión vida-muerte que se había planteado desde el comienzo de la narración, también se identifica como el punto donde convergen tanto el flujo narrativo lineal como el parabólico. Dicho desenlace resulta coincidir con el prevalecer de la "voluntad" (ANDERSON IMBERT, 1992, 25) que desde el principio quedaba descrita como dominante, es decir con la muerte de los personajes que protagonizan cada derrota, lo cual, recuperando las palabras de Méndez sobre el género cuento, matiza el alcance del adjetivo 'sorpresivo'. Todas las líneas temáticas hasta ese momento fluctuantes dentro de la complejidad de una narración tan multiforme y plástica convergen, entonces, hacia la misma idea anonadante de derrota que es, a la vez, una cicatriz transversal en relación con el siglo XX español y una antorcha para las generaciones que desempeñan a principios del tercer milenio el papel de articuladoras de la memoria pública -eso es, la de los niños y de los nietos-, para que busquen y exijan un duelo no

\footnotetext{
29 "Descubrí que el metro olía a ropa usada, tenía la temperatura del aliento y estaba iluminado con la misma luz que suele haber en la habitación donde se mueren los enfermos. [...] Aquellos túneles eran el lugar donde se escondían los leprosos.[...] A medida que pasaban los días mi padre estaba cada vez más tiempo en el armario. Todo empezó a impregnarse de tristeza. Me sentí culpable porque aquel armario empezó a adquirir el olor del Metro y a mí me parecía que eso terminaría atrayendo a los leprosos" (MÉNDEZ, 2008, p.148-49).
} 


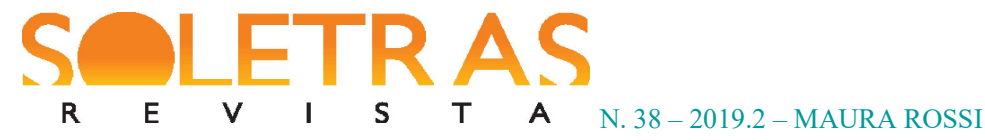

excluyente ni banderizo, ni olvidadizo o falsamente conciliador, sino polifónico, consciente y, por fin, 'civil'.

\section{Referencias:}

ALBIZU YEREGUI, Cristina. Literatura y memoria: amalgama discursiva y reflexión metaliteraria en Los girasoles ciegos de Alberto Méndez. Triunfo del discurso metaliterario sobre la derrota histórica. Versants, 56.3, 2009, p. 67-83.

ANDERSON IMBERT, Enrique. Teoría y técnica del cuento. Barcelona: Ariel, 1992.

BECERRA MAYOR, David. La guerra civil como moda literaria. Madrid: Clave Intelectual, 2015.

BERTRAND DE MUÑOZ, Maryse. Las grandes tendencias de la novela de la guerra civil en siglo XXI. Revista canadiense de estudios hispánicos, v. 36, 1, 2011, p. 207-226.

CORTÁZAR, Julio. En torno al cuento. Cuadernos hispanoamericanos, 25, 1971,p. 403-406.

CRUZ SUÁREZ, Juan Carlos. La muerte necesaria. El nombre como lugar posible de memoria en la 'Segunda derrota' de Los girasoles ciegos, en Cruz Suárez, Juan Carlos; González Martín, Diana (eds.): La memoria novelada II. Ficcionalización, documentalismo y lugares de la memoria en la narrativa memorialista española, Bern: Peter Lang, 2015, p. 103-121.

CUERDA, José Luis (director). Los girasoles ciegos, España: Emiliano Otegui (director de producción) et. al., 98', 2008.

FABER, Sebastiaan. Actos afiliativos y postmemoria: asuntos pendientes. Pasavento, v. 2, 1, 2014, p. 137-155.

GARINO-ABEL, Laurence. El relato ficcional histórico: entre literatura personal y testimonio (Alberto Méndez, Los girasoles ciegos), en Tyras, Georges; Vila, Juan (eds.): Memoria y testimonio: representaciones memorísticas en la España contemporánea. Madrid: Verbum, 2012, p. 216-227.

GÓMEZ LÓPEZ-QUIÑONEZ, Antonio. La guerra persistente. Memoria, violencia y utopía: representaciones contemporáneas de la guerra civil española. Frankfurt: IberoamericanaVervuert, 2006.

HIRSCH, Marianne. The Generation of Postmemory: Writing and Visual Culture After the Holocaust, New York: Columbia University Press, 2012.

INXAUSTI, Aurora.Lacruda mirada de Alberto Méndez sobre laposguerra gana el 'Nacional de Narrativa'. El País, 7 de octubre, 2005, s.n. 


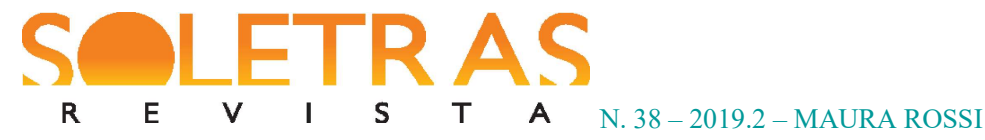

LÓPEZ GUIL, Itzíar; AlbizuYeregui, Cristina (eds.). Los girasoles ciegos de Alberto Méndez, diez años después. Madrid: A. Machado Libros, 2015.

LOUGH, Francis. Ideology, affect and the body in Alberto Méndez's Los girasols ciegos. Bulletin of Hispanic Studies, v. 94, 8, 2017, p. 847-861.

MARTÍNEZ DE PISÓN, Ignacio. Arañar el tiempo. El Pais, 7 de octubre, 2005, s.n.

MARTÍNEZ RUBIO, José. Las formas de la verdad. Investigación, docuficción y memoria en la novela hispánica. Barcelona: Anthropos, 2015.

MAUREL, Marcos. Los desastres de la guerra. Cuadernos Hispanoamericanos, 651-652, 2004, p. 271-273.

MÉNDEZ, Alberto. En torno al cuento. Discurso de agradecimiento por la entrega del Premio Setenil, 2004, s.n. Disponible en la web del Ayuntamiento de Molina de Segura (http://portal.molinadesegura.es/images/literario/setenil/Setenil2004-01.pdf, 28/05/2019).

MÉNDEZ, Alberto. Los girasoles ciegos. Barcelona: Anagrama, 2008.

MOLERO BENAVIDES, José Antonio. Alberto Méndez gana a título póstumo el 'Premio Nacional de Narrativa' 2005. Gibralfaro, v. IV, 35, 2005.

NUCKOLS, Anthony. La novela contemporánea como instrumento del duelo. Los girasoles ciegos de Alberto Méndez. Revista internacional de los estudios vascos, n. extra 8, 2008, p. 180-199.

ORSINI-SAILLET, Catherine. La memoria colectiva de la derrota: Los girasoles ciegos de Alberto Méndez, en VV. AA.: Actas del congreso internacional "La guerra civil española, 1936-1939”. Madrid: Sociedad Estatal de Conmemoraciones Culturales (recurso digital), 2006.

RENDUELES, César. Alberto Méndez. La vida en el cementerio.12.LDNM, septiembreoctubre, 2004.

ROSSI, Maura. La memoria transgeneracional. Presencia y persistencia de la guerra civil en la narrativa española contemporánea. Bern: Peter Lang, 2016.

SANTAMARÍA, Sara. Los girasoles ciegos de Alberto Méndez: ¿un 'lugar de memoria' de la guerra civil? Pasajes, 24, 2007, p. 123-129.

TRECCA, Simone. Retorica della citazione in Los girasolesciegos di Alberto Méndez, en Sarmati, Elisabetta; Trecca, Simone (ed): La biblioteca dello scrittore. Percorsi intertestuali nella narrativa spagnola contemporanea (Laforet, Puértolas, Marias, Méndez, Neuman), Roma: Nuova Cultura, 2012, p. 133-150. 


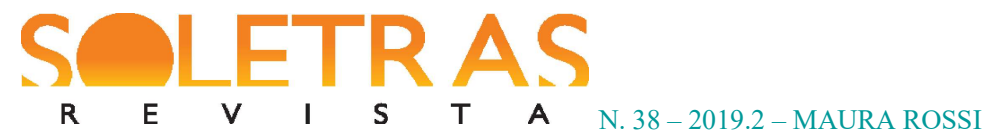

\title{
Alberto Méndez's narrative facing the entropy of trauma. On Blind Sunflowers
}

\begin{abstract}
Alberto Méndez's Blind Sunflowers is a collection of four short stories first published in 2004 in the context of then recently revitalized 'literature of memory', within the broader framework of Spanish ultracontemporary literature. The aim of this work is to propose a detailed analysis of those aspects which link the content of the stories therein narrated with the technical characteristics of the chosen genre, with the ultimate objective of deciphering the personal declination of the short story developed by Méndez, along with its contribution to the trans-literary debate on the shared memory of the trauma of the Spanish Civil War and Francoism. The ultimate aim of the argumentation here exposed is to comment on the concept of 'universal defeat' articulated by the author, on its diverse modulations within the text and on the modalities of configuration of a shared grief which could eventually pacify the inherited memory of a historical period which is as recent as it is controverted.
\end{abstract}

Keywords: Alberto Méndez. Blind Sunflowers. Postmemory. Spanish Civil War. Short story.

Recebido em: 25 de julho de 2019.

Aceito em: 16 de agosto de 2019. 